\title{
Seismic Hydrodynamic Pressure of Bridge Pier in Deep Water
}

\author{
Zhang Shiwang 1, a , Tao Xiaxin 2, 1, b, Liu Haiming ${ }^{3, c}$
}

${ }^{1}$ Key Laboratory of Earthquake Engineering and Engineering Vibration, Institute of Engineering Mechanics, China Earthquake Administration, Harbin, 150080, China

${ }^{2}$ School of Civil Engineering, Harbin Institute of Technology, Harbin, 150090, China

${ }^{3}$ China Merchants Chongqing Communication Research \& Design Institute Co., Ltd, State Key

Laboratory of Bridge Engineering Structural Dynamics, Chongqing, 400067, China

a635994080@qq.com, btaoxiaxin@aliyun.com, ${ }^{b}$ liuhaiming@cmhk.com

Keywords: Hydrodynamic pressure, Seismic design, Bridge pier, Deep water

Abstract. The feasibility of a modified formula for seismic hydrodynamic pressure on pier in deep water in design of highway bridges is discussed in this paper. Several recent results of dynamic response analyses of bridge piers in deep water by various approaches are compared with the values from the formula numerically. It is shown that the results increase with water depth in a consistent trend as the curves by means the suggested formula, at least in the range of depth less than $60 \mathrm{~m}$. The formula is conservative in the range of depth greater than 80, even at depth of $168 \mathrm{~m}$.

\section{Introduction}

In seismic design of highway bridges, the effect of earthquake ground motion must be combined with those by some other loads such as dead load and so on. Hydrodynamic pressure is one of those loads, especially for the bridge pier in deep water. A set of formulas on seismic hydrodynamic pressure are stipulated in the existing guidelines for seismic design of highway bridges of China [1], and a modification is suggested recently [2]. In China, many bridges have been built in deep water environment, some of them in water depths more 100m. Several dozen papers on seismic response of bridges with piers in deep water have been published in these years. The feasibility of the modified formulas is studied by means of comparing the resultant force values with these recent results.

\section{The modified formulas for seismic hydrodynamic pressure}

In order to update the two errors from a misprint and a slip up on the formulas in the existing guidelines for seismic design of highway bridges of China [1], a modification of the formulas with consulting those in Japanese specifications and with considering simple and convenience in design practice of highway bridges, is suggested as follows [2].

$$
\begin{aligned}
& \left.E_{\bar{W}} 0.751 .0-\frac{b}{4 h}\right) C_{i} A \xi_{h} \gamma_{w} b^{2} h / g, \quad \text { if } \frac{b}{h} \leq 2.0 \\
& E_{\bar{W}} 0.375 C_{i} A \xi_{h} \gamma_{w} b^{2} h / g, \quad \text { if } 2.0<\frac{b}{h}
\end{aligned}
$$

where $E_{\mathrm{w}}$ is the resultant force of total seismic hydrodynamic pressure acted on the pier at height of $h / 2$ $(\mathrm{kN}), C_{i}$ is importance factor, $A$ is horizontal design basic peak ground acceleration, $g$ is the gravity acceleration, $h$ is the water depth $(\mathrm{m}), b$ is the pier width in the direction perpendicular to the direction of hydrodynamic pressure $(\mathrm{m}), \xi_{\mathrm{h}}$ is section shape factor with value 1.0 for rectangular and 0.8 for circular, $\gamma_{\mathrm{w}}$ is unit weight of water $\left(\mathrm{kN} / \mathrm{m}^{3}\right)$.

It is obvious that the sectional force of pier caused by seismic hydrodynamic pressure from the formulas such as Eq. 1 must be calculated by static method. It is mentioned in the guidelines that the 
resultant force by hydrodynamic pressure shall be combined with the inertia force caused by ground motion and effect of other loads by both dynamic or static procedure, and the force can be assumed to act in the same direction of the inertia force. In Japanese design specifications for highway bridges, Part V seismic design [3], the lateral strength and ductility capacity of the pier be calculated and verified with the response ductility ratio by the combination of all forces including that from the seismic hydrodynamic pressure for Level 2 or Level 3 earthquake.

The authors of this paper are going to see if the Eq. 1 is feasible for the seismic design of bridge pier in deep water, since Eq. 2 is just for shallow water from the general pier size.

\section{Recent results of bridge piers in deep water and comparison with those from Eq. 1}

The seismic response of bridge with piers in deep water is a quite complicated dynamic interaction problem of a fluid-solid coupling dynamics, so numerical methods are adopted in all recent papers piers in deep water. The compressibility of water is ignored; pier and water are discretized by finite element and/or boundary element method. The action of water wave on pier involves effects of viscosity, inertia force and diffraction. The second effect is simulated by added mass of entrained water which reduces the natural frequency of the pier. Totally 37 references on seismic response of bridge piers under hydrodynamic pressure are reviewed, but will not all listed here since space limitation. Most methods of them are mainly based on Morison equation that is a semi empirical and semi analytical approach, and it ignores the action of the pier on wave field, thus is propitious to the thin pier. The values of two parameters for dynamic inertia and viscosity of water are from relative codes. The response time history calculation can be carried out by means of a commercial software tool, MIDAS. Some results are from linear diffraction wave theory in which the wave field is broken by the piers; the total wave field consists of both scattered wave and input wave. The fluid-solid coupling dynamic interaction is deal with in a few papers, where the force acted on a node of pier surface and velocity at that point must continuing with those on the next node of water mass, and worked out on software ADINA.

Many factors have been taken into account in the analyses, with different pier heights, water depths, bridge types and span lengths, linear or/and nonlinear constitutive model of pier, horizontal and vertical input motions with different time histories and intensities 7 or 8 , input along or transversal bridge directions, even the added mass from Japanese or Euro code. Therefore, there must be many differences among the results. In order to compare the results on one figure, a normalized index must be designed. In general, sectional forces at some sections of bridge members are presented in the references, in which the moment or/and shear force at pier bottom are the most convenient to derive the force from hydrodynamic pressure. An influence coefficient of internal force, say shear, is widely adopted for the effect of the pressure defined as following.

$$
\mathrm{R}=\frac{\mathrm{F}-\mathrm{F}_{0}}{\mathrm{~F}_{0}}
$$

where $F$ is the maximum seismic response value with taking into account hydrodynamic pressure for given water depth, $F_{0}$ is the maximum seismic response value without considering on the pressure. It is clear that the $F_{0}$ depends not on water depth, and the difference between $F$ and $F_{0}$ is just the resultant force of hydrodynamic pressure, therefore the ratio of $R$ 's must be the ratio of the resultant forces.

The ratio of the $R$ from a given water depth to $R$ from 10 meters is adopted from results of five references as shown in Fig. 1. For a comparison, the curves for four $b$ values in the corresponding results are also showed in the figure. 


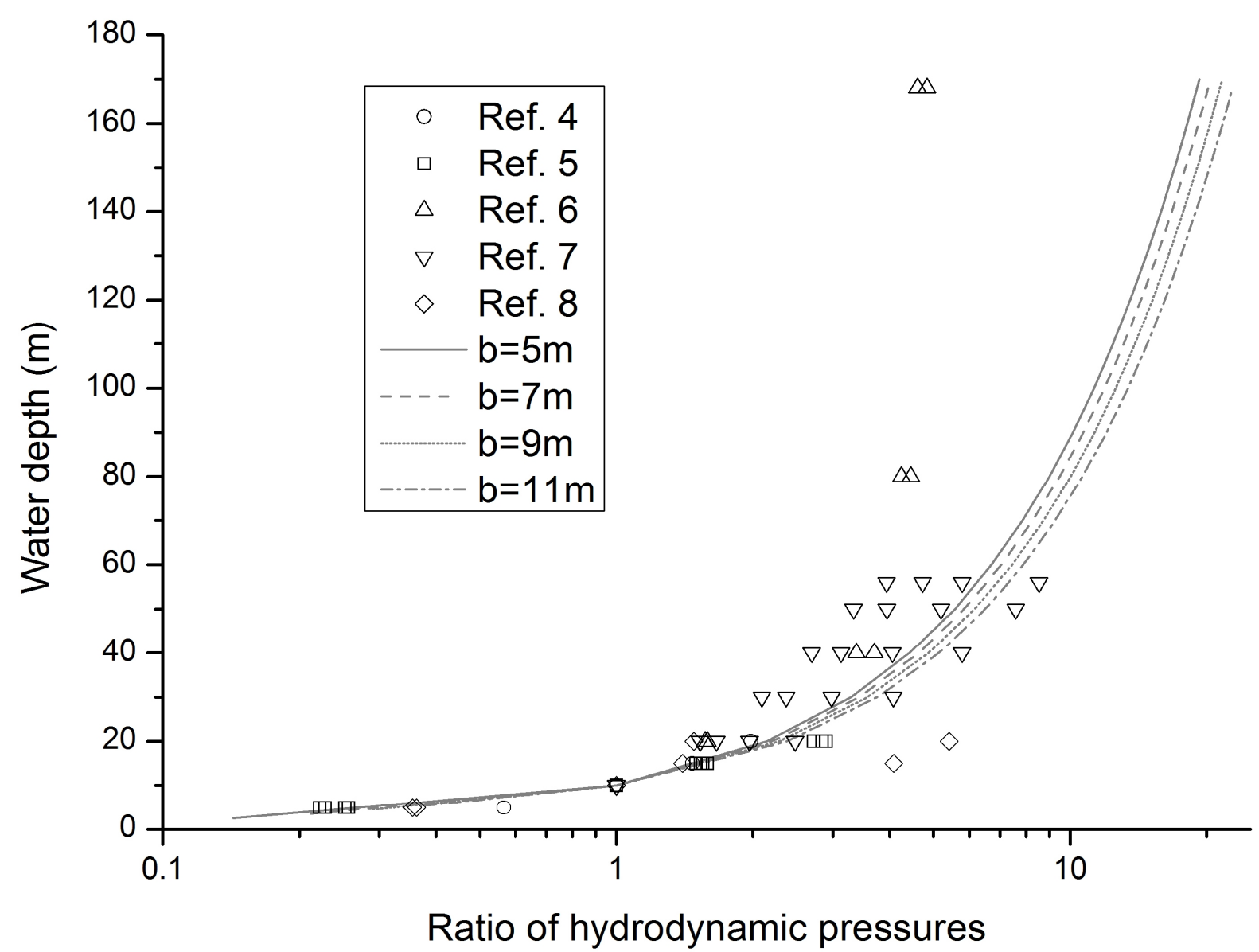

Fig. 1 Ratio of hydrodynamic pressures with various water depths

One can see from the figure that the results of various numerical dynamic responses increase with water depth in a consistent trend as the curves by means of Eq.1, at least in the range of water depth less than $60 \mathrm{~m}$. Just one result shows that the pressure no longer increases with water depth in the range of depth greater than $80 \mathrm{~m}$, and the ratio of $R$ 's keeps almost a value of 5.0 even at a depth $168 \mathrm{~m}$. That means Eq. 1 is conservative for deep water situation.

\section{Conclusions}

In order to verify the feasibility of a modified formula for seismic hydrodynamic pressure on pier in deep water in design of highway bridges, recent results of numerical response analysis of bridge piers by various dynamic approaches are compared with the values from the formula. It is shown that the results increase with water depth in a consistent trend as the curves by means the suggested formula, at least in the range of water depth less than $60 \mathrm{~m}$. The formula is conservative in the range of depth greater than $80 \mathrm{~m}$, even at depth of $168 \mathrm{~m}$.

This conclusion will be validated further from the results of the rest references that there is no direct influence coefficient data, but can be estimated with some amount of calculation. From the preliminary result of this paper, the idea to calculate hydrodynamic pressure by formulas as Eq. 1 for shallow water situation, and by numerical dynamic response analysis with added mass for deep water situation, is not necessary at present, since there are so many choices of methods, models, parameters, factors, and we don't know which is the best now.

Finally, it seems can be mentioned that the added mass estimated from Euro code 8 must be more conservative, since the mass from Eq. 1 is less than that from the code, and the preliminary conclusion of this paper that Eq.1 is conservative for deep water. 


\section{Acknowledgements}

This work was financially supported by grant of Basic Scientific Research Foundation of Institute of Engineering Mechanics for Special Operations (2013B14); funds of State Key Laboratory of Bridge Engineering Structural Dynamics and Key Laboratory of Bridge Earthquake Resistance Technology, Ministry of Communications, PRC; and 51678540 and 51778197 of National Nature Science Foundation of China.

\section{References}

[1] Ministry of Transport of the People's Republic of China. 2008. Guidelines for Seismic Design of Highway Bridges (JTG/T B02-01-2008, in Chinese).

[2] Liu H. and X. Tao: A discussion on formulas of seismic hydrodynamic pressure, submitted to IFCAT2017 (2017)

[3] Japan Road Association: 2002 Design Specifications for Highway Bridges, Part V Seismic Design (2002).

[4] Gao X., X. Zhu: Hydrodynamic effect on seismic response of bridge piers in deep water. Journal of Beijing Jiaotong University: Natural Science, Vol. 30 (2006), P. 55-58.

[5] Li Y.: Study on the effects of hydrodynamic force on the dynamic performance of deep-water bridges subjected to strong earthquake. Doctor degree dissertation, University of Science and Technology Beijing (2010).

[6] Liu Z.: The earthquake response study of deep-water bridges. Doctor degree dissertation, Southwest Jiaotong University (2008).

[7] Zhang J., J. Zeng, and D. Zhu: Influence of hydrodynamic pressure on seismic response of piers in deep water. Journal of Chongqing Jiaotong University: Natural Science, (2014), p. 22-28.

[8] Sun J., Y. Pan: Seismic response comparison of hydrodynamic pressure on bridge pier in deep water. Technology \& Economy in Areas of Communications Vol. 15 (2013), p. 39-42. 